\title{
Long-Lasting Changes in Morphine-Induced Locomotor Sensitization and Tolerance in Long-Evans Mother Rats as a Result of Periodic Postpartum Separation from the Litter: A Novel Model of Increased Vulnerability to Drug Abuse?
}

\author{
Mikhail Kalinichev*,', Keith W Easterling' and Stephen G Holtzman' \\ 'Department of Pharmacology, Rollins Research Center, Emory University School of Medicine, Atlanta, GA, USA
}

\begin{abstract}
Daily postpartum separations from the litter produce enduring changes in anxiety and sensitivity to the antinociceptive effects of morphine in Long-Evans dams. We tested whether postpartum experience alters sensitivity to the effects of morphine on locomotor activity. Dams were tested 4-6 weeks after their pups were weaned, and had one of the following backgrounds: daily separation from the litter on postpartum days 2-14 for either $3 \mathrm{~h}$ (prolonged separation-LS) or $15 \mathrm{~min}$ (brief separation-BS), or no separation (nonhandled control- NH). After 2 consecutive days (BI-2) of baseline activity measurements, subjects were tested daily after s.c. injections of either morphine $(10 \mathrm{mg} / \mathrm{kg}$ ) or saline for 7 days and again on day 10 . Beginning 5 days later, saline and $1.0-10 \mathrm{mg} / \mathrm{kg}$ of morphine were tested in all dams. On BI, LS and BS dams habituated slower than NH controls, yielding higher horizontal counts. LS dams failed to habituate across baseline days and were more active than other dams on B2. Sensitization, a progressive increase in horizontal activity, was more rapid and robust in LS and BS dams compared to NH animals. LS was the only group that developed tolerance to morphine-induced decreases in vertical activity. In LS dams with the history of morphine treatment, injection of saline resulted in higher horizontal activity and center time compared to saline-treated counterparts, indicative of conditioning. Among animals with a history of saline treatment, LS dams were more sensitive to morphine challenges than BS and NH dams. As a result of the robust and long-lasting increases in the ability of morphine to induce behavioral sensitization in litter-separated dams, periodic postpartum separation may represent a new animal model of increased vulnerability to substance abuse.

Neuropsychopharmacology (2003) 28, 317-328. doi: I 0.1038/sj.npp. 1300068
\end{abstract}

Keywords: postpartum experience; opioids; habituation; attention/learning; conditioning

\section{INTRODUCTION}

The results of extensive research during the last few decades provide ample evidence that both in humans and in animals early neonatal environment plays an important role in shaping an organism's physiology and behavior. For most newborn mammals, the mother is the major source of environmental stimulation; therefore, even minor perturbations in mother-infant interactions result in enduring changes in the offspring. For example, in humans, even suboptimal levels of nurturance during childhood can lead to increased vulnerability to mental illness as well as to substance abuse in adult life (Servant and Parquet, 1994;

*Correspondence: Dr M Kalinichev, Behavioral Neurobiology, Schizophrenia \& Bipolar Disorders Research, Psychiatry CEDD, GlaxoSmithKline Plc, Third Ave., Harlow CMI9 5AW, UK, Tel: +44 I279 627I22, Fax: +44 1279 875389, E-mail: mikhail.m.kalinichev@gsk.com

Received 22 May 2002; revised 13 September 2002; accepted 16 September 2002

Online publication: 20 September 2002 at http://www.acnp.org/ citations/Npp092402389
Triffleman et al, 1995; Young et al, 1997; Bernet and Stein, 1999; Medrano et al, 1999). In the rat, the amount of maternal care (licking/grooming and arched-back nursing) an animal receives in infancy shapes its life-long behavioral and neuroendocrine reactivity to novel/aversive environments and other stressors (Liu et al, 1997; Caldji et al, 1998, 2000a). In fact, rats that are raised by mothers naturally low on licking/grooming and arched-back nursing, when tested as adults, resemble animals that experienced prolonged, daily separations from the mother during the first 2 weeks of life (Caldji et al, 1998). Rats that experienced a deficit in maternal care, either naturally or via the procedure of maternal separation, exhibit increases in startle responses and withdrawal behaviors in a novel/aversive environment and increased hypothalamus-pituitary-adrenal (HPA) reactivity to stress (Plotsky and Meaney, 1993; Liu et al, 1997; Wigger and Neumann, 1999; Caldji et al, 1998; Huot et al, 2001; Kalinichev et al, 2002b).

Mother-infant relationships in most mammals, including rats, have been characterized as dyadic and reciprocal (Alberts and Gubernick, 1983). As a result of selective 
responsiveness toward each other, behavioral activities and physiological states of each member of this dyad are, in part, reciprocally regulated by the other member (Alberts and Gubernick, 1983). Therefore, in the rat, in procedures that involve neonatal manipulations of the young, such as maternal separation, it is virtually impossible not to impact the other member of this dyad-the mother. While the long-lasting effects of mother-litter separation on the offspring have been extensively investigated, far fewer studies have addressed whether these manipulations can lead to enduring changes in the mother. Periodic separations from the offspring alter maternal behavior of the dam, even though the exact nature of this impact is still debated (Lee and Williams, 1974; Liu et al, 1997; Boccia and Pedersen, 2001; Pryce et al, 2001). We provided the first evidence that in the rat, the impact on the dam of periodic separations from the litter is long lasting and involves fear/ anxiety neural networks as well as endogenous opioid systems (Kalinichev et al, 2000). Indeed, the maternal neural system is involved in active 'crosstalk' with the fear/ anxiety-mediating neural system (Fleming et al, 1980, 1988, 1989; Fleming and Luebke, 1981) and is modulated by endogenous opioids (Mayer et al, 1985; Panksepp et al, 1994; Zaias et al, 1996; Nelson and Panksepp, 1998; Byrnes and Bridges, 2000).

In this study, we continued to investigate the possible link between postpartum experience and long-lasting changes in opioid systems. We addressed the question of whether periodic postpartum separation from the offspring can result in long-lasting changes in sensitivity to repeated morphine administration. In the rat, repeated intermittent injection of morphine can result in two phenomena: an enhancement of the locomotor-stimulant action of the drug (ie sensitization) or attenuation of the motor-depressant action of the drug (ie tolerance; Babbini and Davis, 1972; Brady and Holtzman, 1981; Bartoletti et al, 1983; Kalivas and Stewart, 1991; Stewart and Badiani, 1993; Rauhala et al, 1995; Powell and Holtzman, 2001). Behavioral sensitization as a result of repeated intermittent morphine administration has been studied extensively to understand such phenomena as drug seeking, drug taking, and relapse behaviors that characterize addiction (Wise and Bozarth, 1987; Robinson and Berridge, 1993; Berridge and Robinson, 1995). We evaluated the effect of repeated morphine administration on the locomotor activity of Long-Evans dams that had experienced either prolonged (3-h), brief (15$\mathrm{min}$ ), or no separations from the offspring during the first 2 weeks postpartum. Long-lasting changes in sensitivity to morphine as a result of postpartum separation may provide a useful new animal model for understanding environmental factors that shape vulnerability to drug abuse in child-bearing women.

\section{METHODS}

\section{Subjects}

Long-Evans hooded primiparous female rats (Blue-Spruce; Harlan Sprague-Dawley Inc., Indianapolis, IN) were tested at approximately 120 days of age, 4-6 weeks after their pups were weaned. A total of 56 dams were used in this study. They were shipped to our facility on the 12th day of pregnancy in three sets containing 20,20, and 16 animals. Food and water were always available ad libitum. The colony room was maintained on a 12:12 light: dark cycle with lights on at $7 \mathrm{am}$. This study was performed in full accordance with the 1996 Guide for the Care and Use of Laboratory Animals (National Academy of Sciences), and the research protocol was approved by the Institutional Animal Care and Use Committee of Emory University.

\section{Postpartum Separation Procedures}

We used a procedure for mother-litter separation (Figure 1) that has been used extensively by our laboratory and other laboratories to evaluate the impact of separation on the offspring (Plotsky and Meaney, 1993; Wigger and Neumann, 1999; Caldji et al, 2000; Liu et al, 2000; Huot et al, 2001; Kalinichev et al, 2001a, b, 2002a, b). The same mother-litter separation procedure induced enduring changes in anxietylike behaviors and sensitivity to antinociceptive effects of morphine in litter-separated dams (Kalinichev et al, 2000). Pups were taken from their mothers, and then randomly redistributed among the dams on postpartum day 2 (date of birth $=$ day 1 ) as all-male (eight pups) litters (Plotsky and Meaney, 1993). A total of 46 dams received all-male litters after the pup redistribution. In addition, following our previous protocol (Kalinichev et al, 2000), some of the dams $(n=7)$ received all-female litters consisting of 10 pups, to approximate the total weight of an all-male litter. Dams that were raising all-female litters were equally distributed among the postpartum experience groups $(n=2-3 /$ postpartum group). Postpartum experience of prolonged periodic separation (LS) involved removing the entire litter

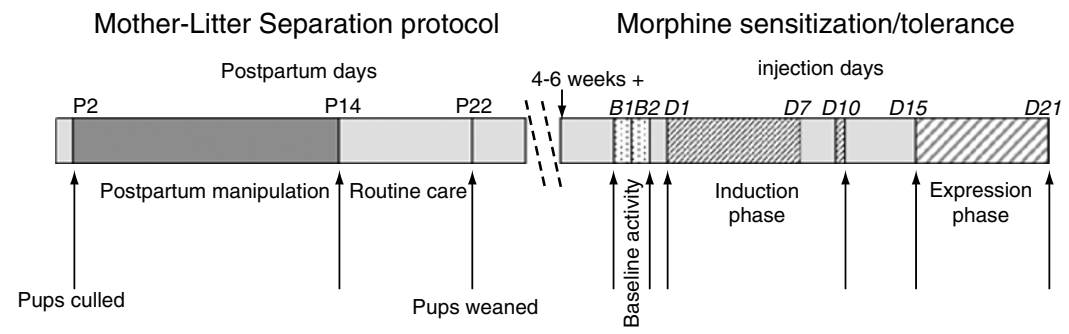

Figure I The time line of the mother-litter separation and morphine-induced sensitization/tolerance procedures. Manipulations were performed on postpartum (P) days 2-14 (see the text). At 4-6 weeks after pups were weaned, dams were tested for baseline activity on 2 consecutive days (BI, B2). During the induction phase $(D I-10)$ they were injected with either $10 \mathrm{mg} / \mathrm{kg}$ of morphine or saline on DI-D7 and DI0. During the expression phase (DI5-2I), all dams were given saline, I.0,3.0, and $10 \mathrm{mg} / \mathrm{kg}$ morphine on DI5, DI7, D I9, and D2I, respectively, and activity was tested after each injection. 
from the dam for $3 \mathrm{~h}$. This was done daily between 0900 and $1200 \mathrm{~h}$ on postpartum days 2-14. Dams that underwent brief periodic separation (BS) experienced a similar procedure, beginning at the same time; however, the pups remained away from the dam for only $15 \mathrm{~min}$. The litters of nonhandled $(\mathrm{NH})$ dams were removed briefly for assignment and pup sexing (postpartum day 2) and thereafter were left undisturbed until weaning. After weaning of pups, dams were kept isolated for 1 week and were then pair-housed with other dams from the same treatment group.

\section{Locomotor Apparatus}

Eight Omitech Digiscan Activity Monitors (Omnitech Electronics Inc., Columbus, $\mathrm{OH})$, equipped with the VersaMax software (Version 1.30, Omnitech Electronics Inc.), were used to measure locomotor activity as described previously (Kalinichev et al, 2000, 2002a). Briefly, each animal was tested in an acrylic box $\left(40 \times 40 \times 30 \mathrm{~cm}^{3}\right)$ surrounded by a framework of photobeams inside a ventilated, sound-attenuating cubicle. Locomotor movements were determined by breaks in photobeams and were converted into locomotor activity counts with the aid of the software VersaDat (Version 1.3; Omnitech Electronics Inc.).

This system provided an automated calculation of several measures of motor activity. Out of several variables we analyzed two key, mutually exclusive behaviors: ambulation (measured in horizontal activity counts) and rearing (measured in vertical activity counts). These behaviors have been used routinely as reliable measures of locomotor activity in the rat (Ivinskis, 1970; Walsh and Cummins, 1976). As we found in our previous (Kalinichev et al, 2002a) and present study (see below), measuring horizontal and vertical activity allows a concomitant assessment of two independent phenomena of neuronal plasticity, behavioral sensitization (via the changes in horizontal activity), and tolerance (via the changes in vertical activity). In addition, time spent in the center of locomotor arenas was analyzed as an index of emotionality in the rat (Valle, 1970; Harro, 1993).

\section{Locomotor Sensitization/Tolerance (Induction Phase)}

The procedure (Figure 1) was the same one that we used to study morphine-induced locomotor sensitization/tolerance in maternally separated offspring (Kalinichev et al, 2002a). The baseline locomotor activity was measured for $2 \mathrm{~h}$ daily on 2 consecutive baseline days (B1 and B2). The horizontal activity of two dams (BS and $\mathrm{NH}$ ) on $\mathrm{B} 1$ exceeded the corresponding group means by more than three standard deviations. These animals, as well as one dam (BS) that died after receiving morphine on the first day of injections, were excluded from further analysis. At 24$48 \mathrm{~h}$ after the second baseline session (injection day 1) animals received an injection of either $10 \mathrm{mg} / \mathrm{kg}$ of morphine (morphine group) or saline (saline group) immediately before being placed in the testing chambers for 2-h sessions. Injections continued daily for 7 days (Figure 1). On days 3, 5, and 7, dams were tested for locomotor activity $(2 \mathrm{~h})$ immediately after receiving the injection. On days 2, 4, and 6, animals received the appropriate injection in the home cage. On day 10, after a 2-day break from injections and testing, dams were tested for locomotor activity $(2 \mathrm{~h})$ immediately after receiving the group-appropriate injections.

\section{Locomotor Sensitization/Tolerance (Expression Phase)}

A morphine dose-response curve (sal, 1.0, 3.0, $10 \mathrm{mg} / \mathrm{kg}$ ) was determined in all dams across days 15, 17, 19, and 21 (Figure 1). Doses were administered in ascending order, beginning with saline, in order to minimize the influence of morphine on whatever states of tolerance and/or sensitization might exist. No injections were given or tests done on days $11-14,16,18$, and 20 .

\section{Drug}

Morphine sulfate (Penick, Newark, NJ) was dissolved in saline and administered s.c. in a volume of $1.0 \mathrm{ml} / \mathrm{kg}$ body weight. All doses are expressed as the free base.

\section{Data Analysis}

A repeated measures or factorial analysis of variance (ANOVAs) was used to determine if there was a significant main effect. Dunnett's (for comparisons with a single mean) and Fisher's protected least significant difference post hoc tests were used for multiple comparisons. The alpha level chosen was $P \leqslant 0.05$.

\section{RESULTS}

The dams that raised all-male and all-female litters did not differ in any measures of baseline activity. Furthermore, inclusion or exclusion of dams that raised all-female litters ( $n=1-2 /$ postpartum experience/drug treatment group) into the analysis together with the dams that raised all male litters $(n=5-9 /$ postpartum experience/drug treatment group) produced virtually identical results. Therefore, the analyses presented below include all of the dams tested.

\section{Locomotor Activity in a Novel Environment}

Horizontal activity. On baseline day 1 postpartum experience significantly $(\mathrm{F}(2,350)=5.16, p=0.01)$ influenced the rapid decline $(F(7,350)=272.47, p<0.0001)$ of horizontal activity over the 2 -h session in all groups. A significant time $\times$ postpartum experience interaction $(\mathrm{F}(14,350)=2.04, p=0.01)$ indicated that the initial habituation of activity was more rapid in $\mathrm{NH}$ dams compared to other groups (Figure 2a). On baseline day 1, the total number of horizontal counts over $2 \mathrm{~h}$ by LS and BS groups was significantly higher $(\mathrm{F}(2,50)=5.20, p<0.01)$ compared to $\mathrm{NH}$ dams (Figure 2b). On baseline day 2, the total number of horizontal counts by LS dams was significantly higher $(\mathrm{F}(2,50)=12.65, p<0.0001)$ than that of either BS or NH dams (Figure 2c).

Vertical activity. Even though vertical activity declined significantly $(\mathrm{F}(7,350)=185.17, p<0.0001)$ and similarly among the postpartum experience groups, when BS dams 

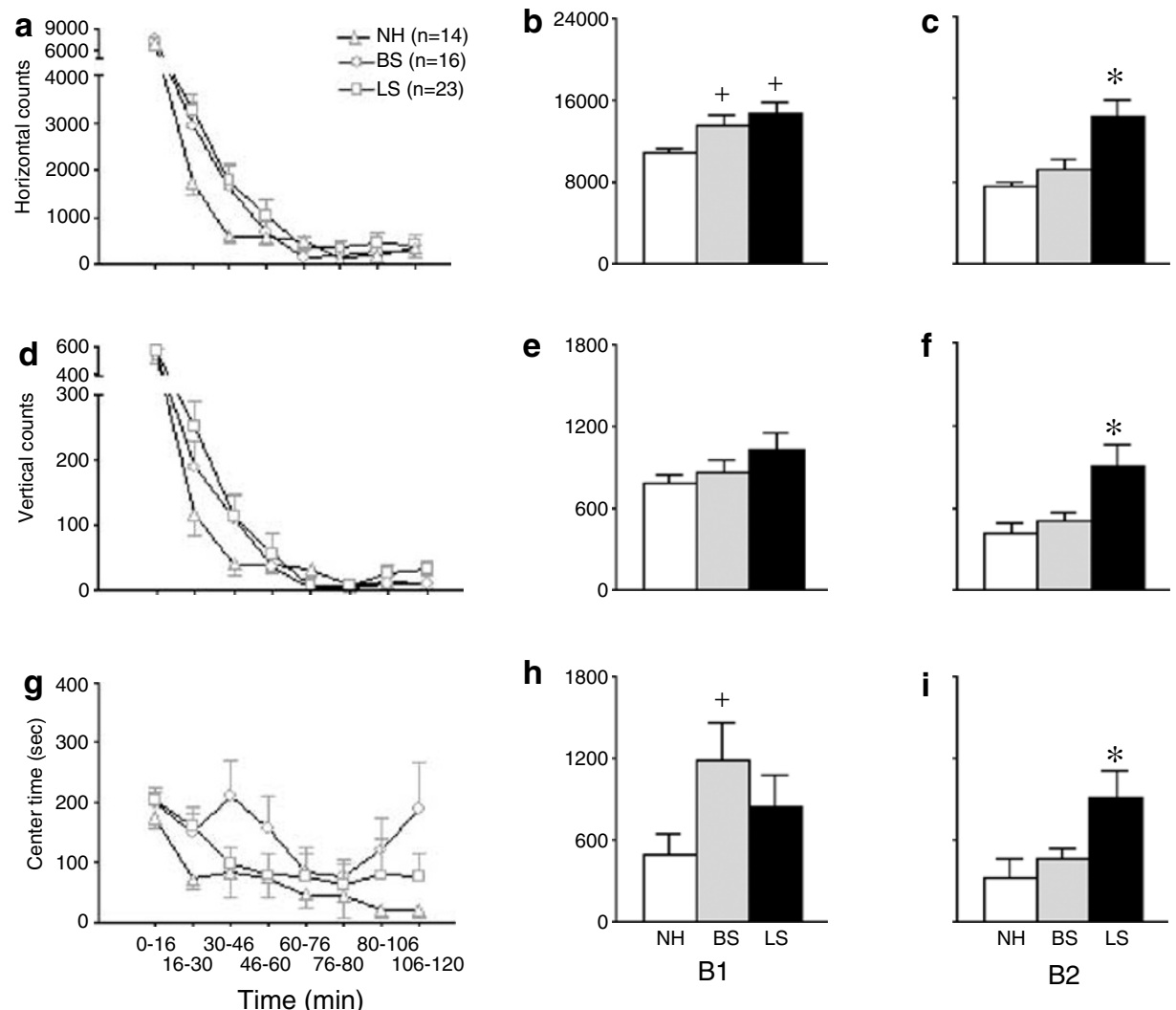

Figure 2 Baseline locomotor activity of $\mathrm{LS}, \mathrm{BS}$, and $\mathrm{NH}$ dams during the first (BI) and second (B2) days of baseline testing. Numbers represent mean ( \pm SEM) of horizontal $(a-c)$, vertical $(d-f)$ activity counts and time $(\mathrm{sec})$ spent in the center of the testing arena (e-i) in I5-min intervals on BI (a, d, $g$ ) or as a total on BI and B2 (b, c, e, f, h, i). $+p<0.05$ compared to NH dams; ${ }^{*} p<0.05$ compared to BS and $\mathrm{NH}$ dams ( $n=14-23 /$ group).

were excluded from the analysis, LS dams were slower to habituate $(\mathrm{F}(7,245)=2.00, p=0.05)$, and had overall higher levels of activity $(\mathrm{F}(1,245)=4.30, p<0.05)$ compared to $\mathrm{NH}$ dams (Figure 2d). While on baseline day 1 there was no difference across the postpartum experience groups in total counts (Figure 2e), on baseline day 2 the total vertical activity of LS dams was significantly higher $(\mathrm{F}(2,50)=8.03, p<0.001)$ than that of either BS or $\mathrm{NH}$ dams (Figure 2f).

Center time. During the 2 -h session of baseline activity on day 1 , the center time declined significantly over time $(\mathrm{F}(7,350)=6.61, p<0.0001$; Figure $2 \mathrm{~g})$. The effect of postpartum experience did not reach statistical significance $(\mathrm{F}(2,350)=2.69, p=0.08)$, and there was no significant time $\times$ postpartum experience interaction. However, the total center time was significantly higher $(\mathrm{F}(2,50)=3.37$, $p<0.05$ ) for BS dams compared to $\mathrm{NH}$ dams (Figure $2 \mathrm{~h}$ ). On baseline day 2 the total center time was significantly higher for LS dams $(\mathrm{F}(2,50)=4.03, p<0.05)$ compared to either BS or NH dams (Figure 2i).

\section{Induction Phase of Locomotor Tolerance/Sensitization}

Horizontal activity. Daily injections of $10 \mathrm{mg} / \mathrm{kg}$ of morphine during the induction phase of sensitization resulted in progressive increases in horizontal counts by all dams: by day 7 , horizontal counts exceeded significantly those on day 1 in all groups (Figure $3 a-c)$. However, the onset of sensitization was more rapid and robust in LS and BS dams: by day 5, activity counts of morphine-treated animals exceeded those of saline-treated controls by almost 4 times $(p<0.05)$. In contrast, on day 5, morphine-treated $\mathrm{NH}$ dams were only 1.6 times more active than salinetreated NH animals. An ANOVA ('postpartum experience' and 'treatment' as between factors, and 'day' as within factor) revealed significant main effects of treatment $(\mathrm{F}(1,188)=26.45, p<0.0001)$ and day $(\mathrm{F}(4,188)=7.47$, $p<0.0001)$, and a significant day $\times$ treatment interaction $(\mathrm{F}(4,188)=10.25, p<0.0001)$; the factor of postpartum experience only approached statistical significance $(\mathrm{F}(2,188)=2.63, p=0.08)$. The time-course comparisons of the groups on treatment days 1 and 10 are presented in Figure 3d-g.

Vertical activity. Initial exposures to $10 \mathrm{mg} / \mathrm{kg}$ of morphine did not change the vertical activity of $\mathrm{NH}$ dams, while reducing the activity of LS and BS dams relative to their saline-treated controls (Figure $4 \mathrm{a}-\mathrm{c}$ ). With daily injections of morphine, the vertical activity of $\mathrm{BS}$ and $\mathrm{NH}$ dams failed to change significantly over 10 days of morphine treatment (Figure $4 \mathrm{a}, \mathrm{b}$ ). In contrast, the vertical activity of LS dams increased significantly over time: by day 10 , vertical counts exceeded those on day 1 (Figure $4 \mathrm{c}$ ). An overall ANOVA revealed a significant main effect of treatment $(\mathrm{F}(1,188)=5.94, \quad p<0.05)$ and day $(\mathrm{F}(4,188)=3.80$, $p<0.01)$ as well as a significant day $\times$ postpartum experience $(\mathrm{F}(8,188)=2.07, \quad p<0.05), \quad$ day $\times$ treatment 

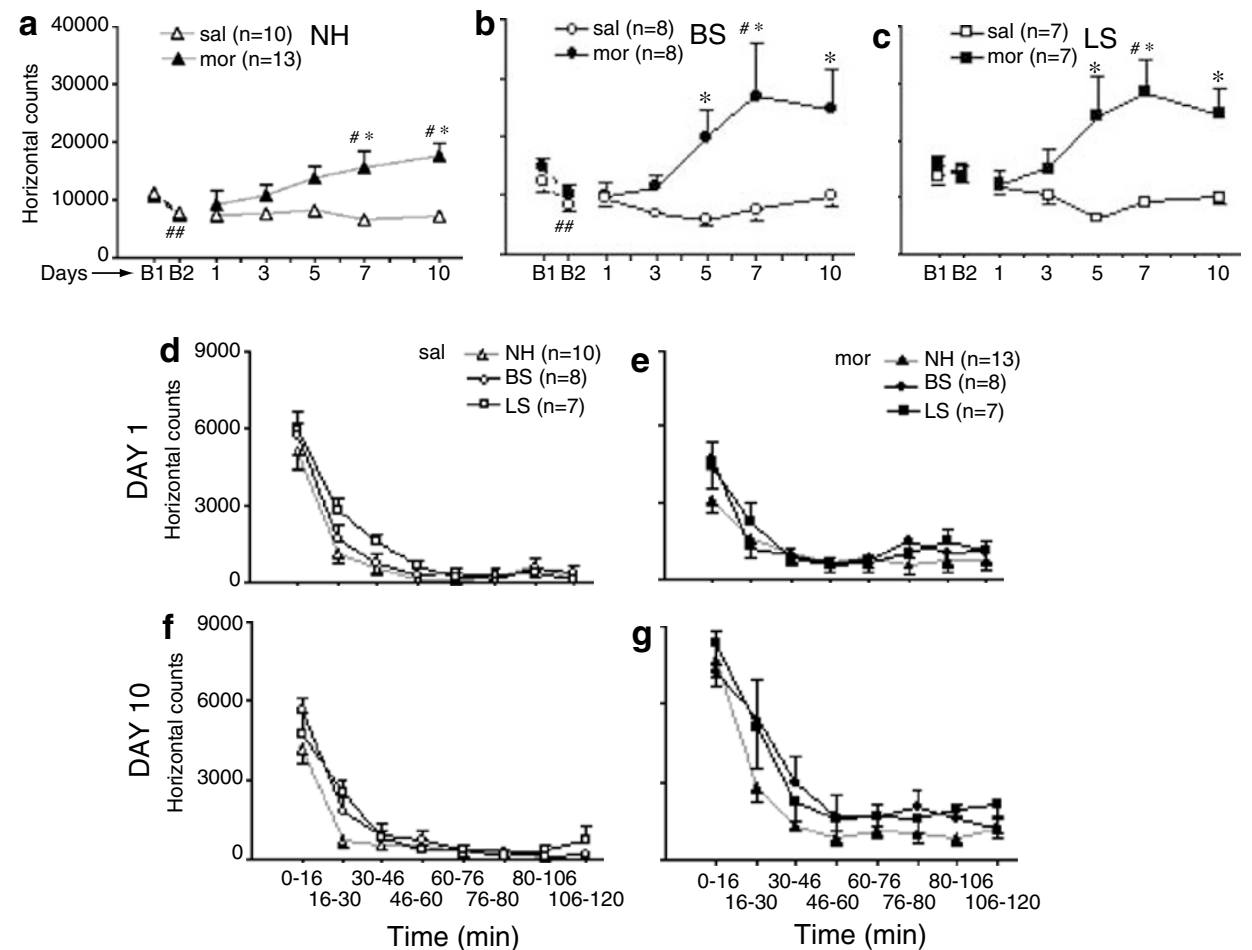

Figure 3 Horizontal activity counts of LS, BS, and NH dams exposed to either saline (sal; open symbols) or $10 \mathrm{mg} / \mathrm{kg}$ of morphine (mor; filled symbols) regimens during the induction phase of sensitization. The points above BI and B2 were reproduced from the data in Figure 2. Numbers represent mean ( \pm SEM) total counts $(\mathrm{a}-\mathrm{c})$ or in I5-min intervals on days I and $10(\mathrm{~d}-\mathrm{g}) . \# p<0.05$ compared to the performance on $\mathrm{BI}$; ${ }^{*} p<0.05$ compared to the corresponding saline group; $\#<0.05$ compared to the performance on injection day I $(n=7-13 /$ group).
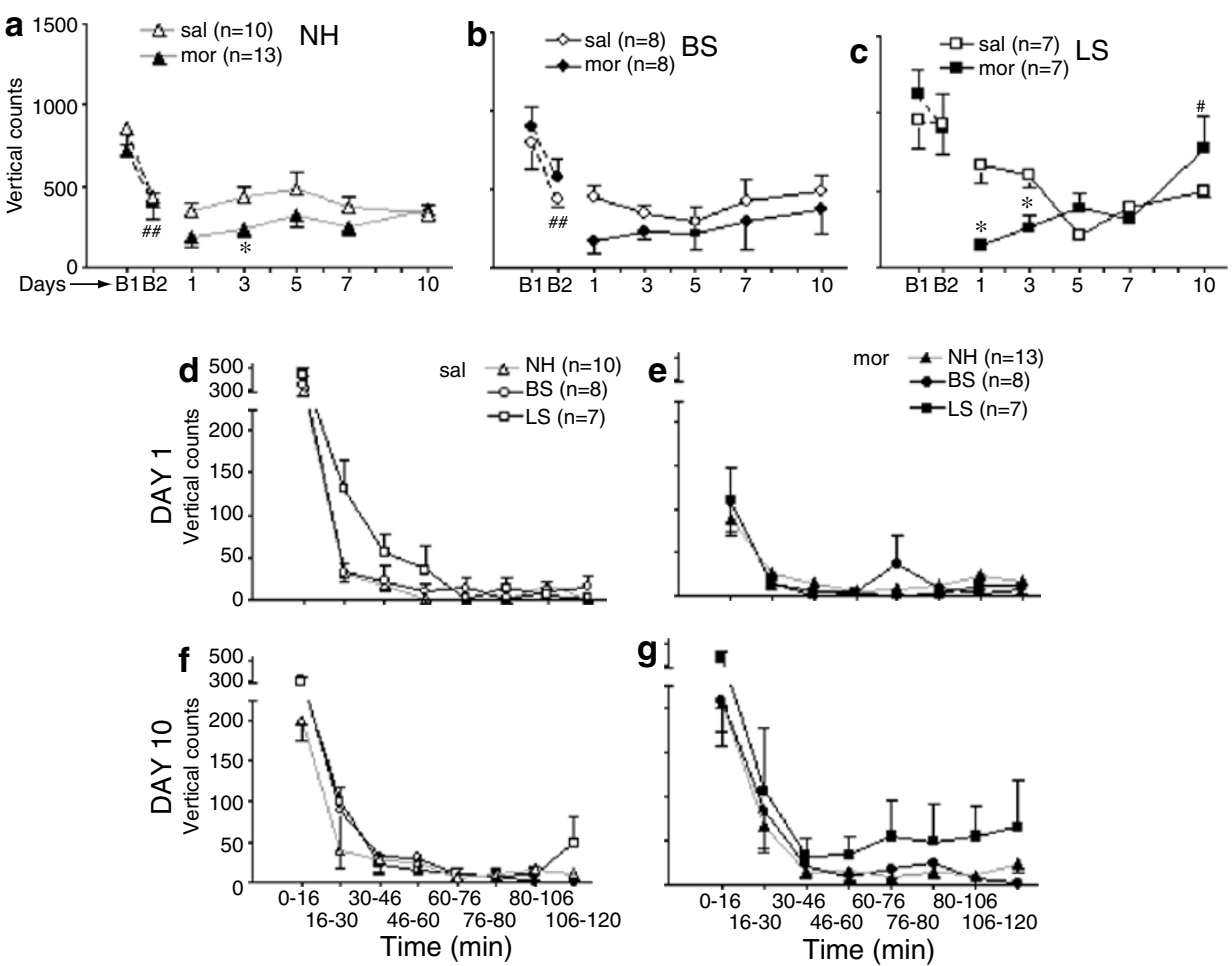

Figure 4 Vertical activity counts of LS, BS, and NH dams exposed to either saline (sal; open symbols) or $10 \mathrm{mg} / \mathrm{kg}$ of morphine (mor; filled symbols) regimens during the induction phase of tolerance. The points above $\mathrm{BI}$ and $\mathrm{B} 2$ were reproduced from the data in Figure 2 . Numbers represent mean ( \pm SEM) total counts $(\mathrm{a}-\mathrm{c})$ or in I5-min intervals on days I and I0 $(\mathrm{d}-\mathrm{g}){ }^{\# \#} \mathrm{p}<0.05$ compared to the performance on $\mathrm{BI}$; * $p<0.05$ compared to the corresponding saline group; $\#<0.05$ compared to the performance on injection day I ( $n=7-\mid 3 /$ group). 
$(\mathrm{F}(4,188)=5.87, p<0.001)$, and day $\times$ postpartum experience $\times$ treatment interactions $(F(8,18)=2.20, p<0.05)$. The time-course comparisons of the groups on treatment days 1 and 10 are presented in Figure $4 \mathrm{~d}-\mathrm{g}$.

Center time. Repeated injections of either morphine or saline failed to alter center time in all groups, even though morphine-treated animals tended to spend more time in the center than their saline-treated counterparts (Figure 5a-c). An overall ANOVA revealed a significant main effect of treatment $(F(1,188)=6.13, p=0.01)$, while the effect of day barely missed reaching statistical significance $(\mathrm{F}(4,188)=2.32, p=0.06)$. The time-course comparisons of the groups on treatment days 1 and 10 are presented in Figure $5 \mathrm{~d}-\mathrm{g}$.

\section{Expression Phase of Locomotor Tolerance/Sensitization}

Horizontal activity. In response to a saline injection, horizontal activity of $\mathrm{NH}$ dams with the history of morphine exposure was virtually identical to that of $\mathrm{NH}$ dams with a history of saline exposure (Figure 6a; points above 'SAL'). In contrast, LS $(130 \% ; t=8.06 ; \mathrm{df}=1,12, p<0.0001)$ and $\mathrm{BS}$ $(70 \% ; t=2.15 ; \mathrm{df}=1,14, p<0.05)$ dams with a history of morphine exposure had significantly higher horizontal counts compared to corresponding saline-history animals (Figure 6b, c; points above 'SAL'). When dams were challenged with increasing doses of morphine, there was a significant main effect of dose on the activity of all animals - LS $(\mathrm{F}(2,18)=14.32, \quad p<0.001), \quad \mathrm{BS}$ $(\mathrm{F}(2,28)=11.55, \quad p<0.001)$, and $\mathrm{NH} \quad(\mathrm{F}(2,42)=32.76$, $p<0.0001)$ dams. There was a significant main effect of previous drug history on the horizontal activity of BS $(\mathrm{F}(1,28)=9.53, \quad p<0.01) \quad$ and $\mathrm{NH} \quad(\mathrm{F}(1,42)=13.70$, $p=0.001)$ dams, but not on the activity of LS animals $(\mathrm{F}(1,24)=3.16, p=0.1)$.

In response to morphine challenge, the overall differences in horizontal activity across groups with a history of saline treatment approached significance $(\mathrm{F}(2,44)=2.99$, $p=0.07)$. Planned comparisons revealed that LS dams were significantly $(p<0.05)$ and consistently more active after challenge doses of morphine than either BS or $\mathrm{NH}$ dams (Figure 6d). Horizontal activity in response to morphine challenge was similar among groups with a history of morphine treatment (Figure 6e).

Vertical counts. Saline injection resulted in similar levels of vertical activity in morphine- and saline-history animals regardless of their postnatal experience (Figure 7a-c; points above 'SAL'). When challenged with increasing doses of morphine, there was a significant main effect of dose on the activity levels of all animals- $\mathrm{NH} \quad(\mathrm{F}(2,42)=7.97$, $p<0.0001)$, BS $\quad(\mathrm{F}(2,28)=14.90, \quad p<0.0001)$, and LS $(\mathrm{F}(2,18)=20.85, p<0.0001)$ dams. Previous drug history failed to influence the vertical activity of $\mathrm{BS}(\mathrm{F}(1,28)=3.63$, $p=0.08)$ and $\mathrm{NH}(\mathrm{F}(1,42)=3.26, p=0.09)$ dams (Figure 7a, b). In contrast, there was a significant dose $\times$ treatment history interaction in the LS group $(\mathrm{F}(2,18)=4.52$, $p<0.05$ ); a post hoc test revealed that morphine-history dams were more active than saline-history animals in response to the two lower doses $(1.0$ and $3.0 \mathrm{mg} / \mathrm{kg})$ of morphine (Figure 7c). Vertical activity in response to morphine challenge was similar among the saline-history (Figure 7d) and morphine-history (Figure 7e) animals.
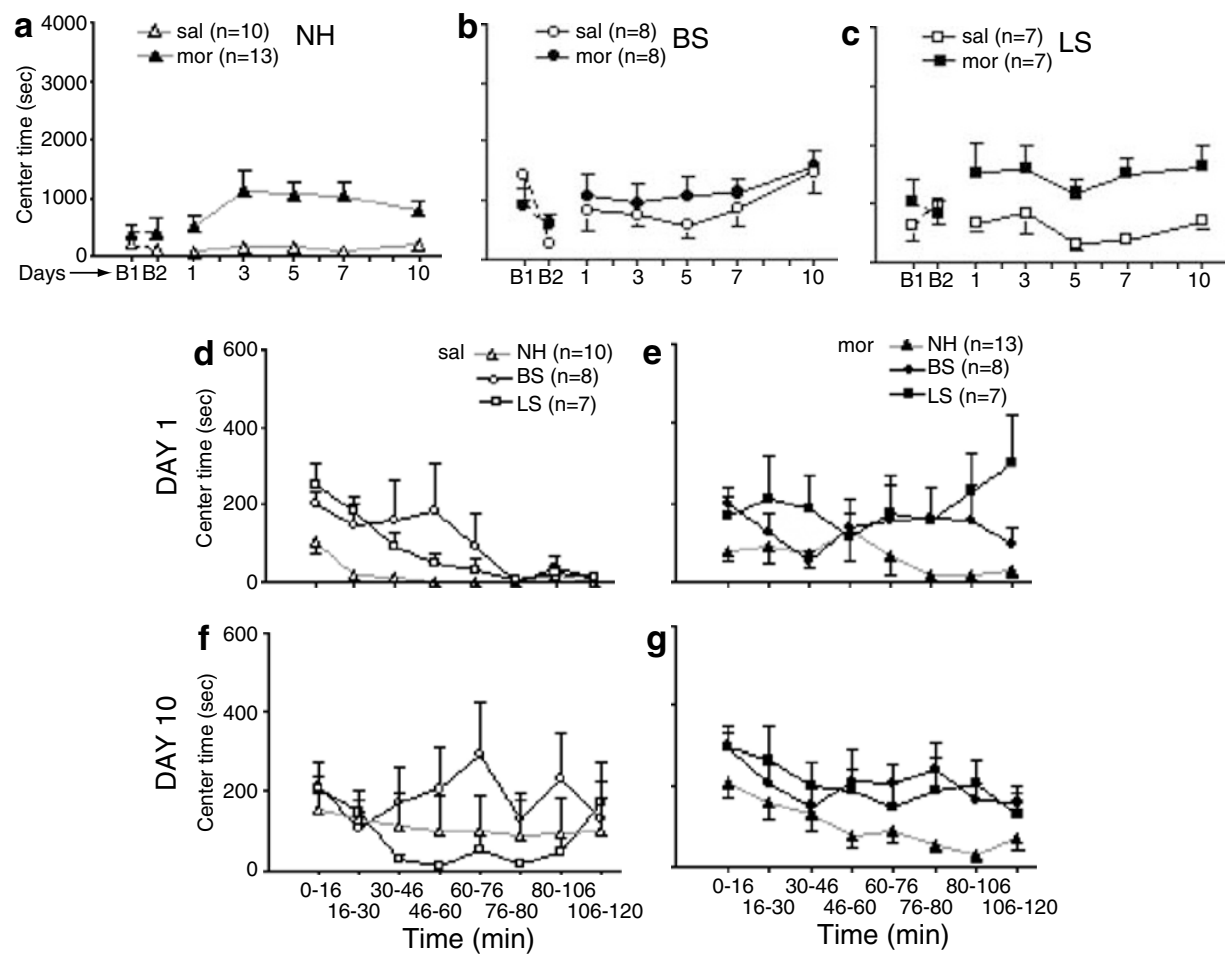

Figure 5 Time (sec) spent in the center of locomotor boxes by LS, BS, and NH dams exposed to either saline (sal; open symbols) or $10 \mathrm{mg} / \mathrm{kg}$ of morphine (mor; filled symbols) regimens during the induction phase of sensitization. The points above $\mathrm{BI}$ and $\mathrm{B} 2$ were reproduced from the data in Figure 2 . Numbers represent mean ( \pm SEM) total counts $(a-c)$ or in 15-min intervals on days I and 10 ( $d-g ; n=7-\mid 3 /$ group). 

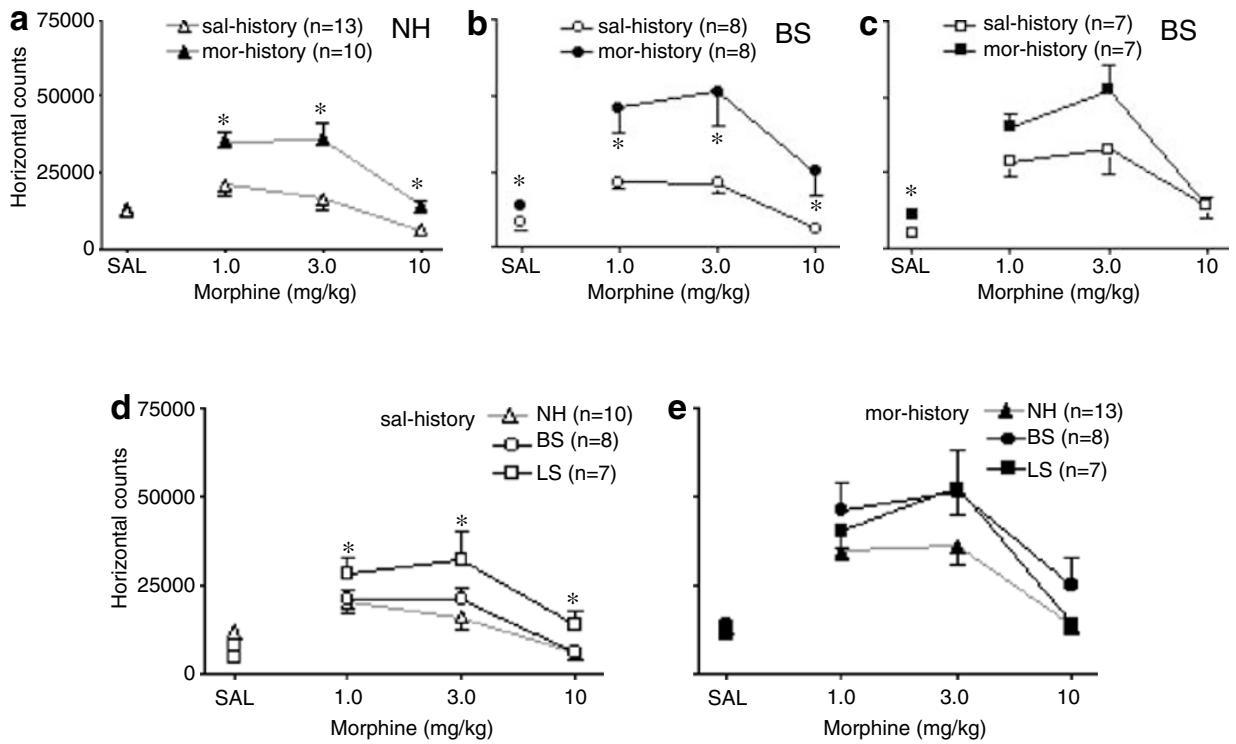

Figure 6 Horizontal activity counts of LS, BS, and NH dams with a history of either saline (sal; open symbols) or $10 \mathrm{mg} / \mathrm{kg}$ of morphine (mor; filled symbols) treatment in response to increasing doses of mor during the expression phase of sensitization. Each point represents the mean $( \pm$ SEM). $* 2<0.05$ compared to the corresponding saline group; * $p<0.05$ compared to BS and $\mathrm{NH}$ dams ( $n=7-$ |3/group).
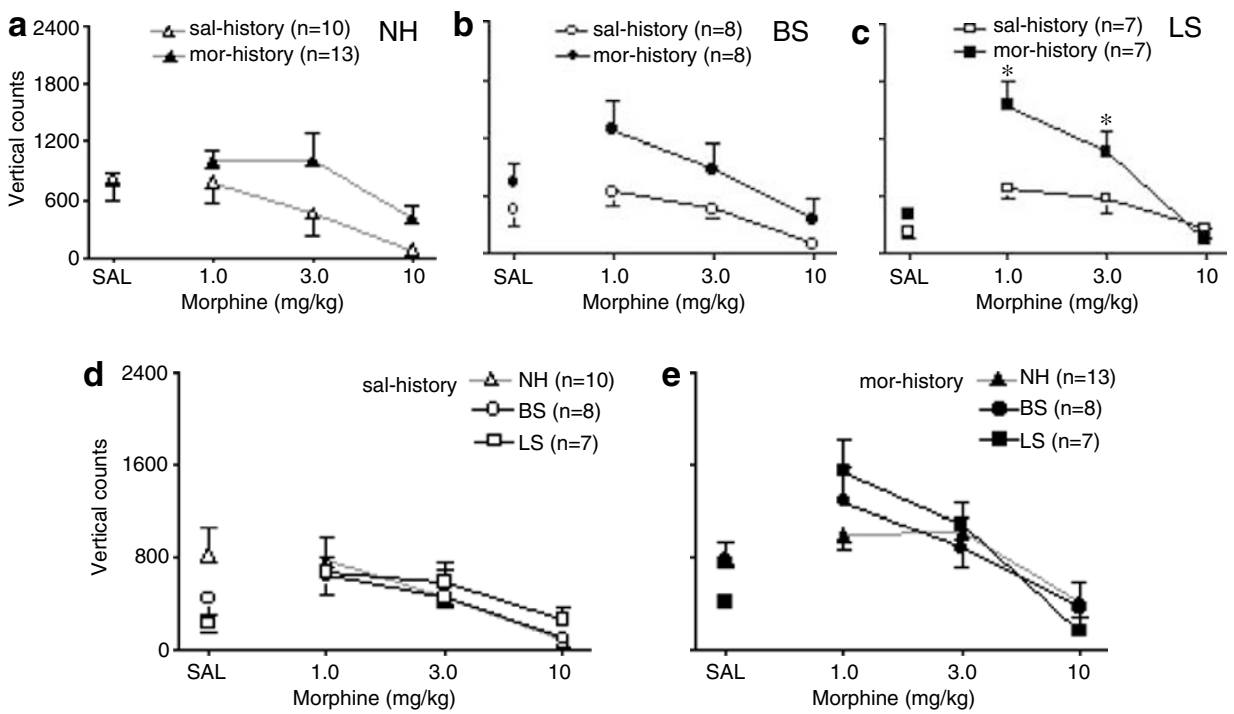

Figure 7 Vertical activity counts of LS, BS, and NH dams with a history of either saline (sal; open symbols) or $10 \mathrm{mg} / \mathrm{kg}$ of morphine (mor; filled symbols) treatment in response to increasing doses of mor during the expression phase of sensitization. Each point represents the mean $( \pm S E M)$. $* 0<0.05$ compared to the corresponding saline group ( $n=7-13$ /group).

Center time. In response to a saline injection, LS was the only group in which dams with a history of morphine exposure had a significantly higher $(120 \%$; $t=2.58$; $\mathrm{df}=1,12, p<0.05)$ center time compared to corresponding saline-history animals (Figure $8 \mathrm{a}-\mathrm{c}$; points above 'SAL'). In response to morphine challenge there was a significant main effect of dose in $\mathrm{BS}(\mathrm{F}(2,28)=10.68, p<0.001)$ and $\mathrm{NH}(\mathrm{F}(2,42)=5.67, p<0.01)$ dams, but not in LS dams $(\mathrm{F}(1,24)=1.76, p=0.2$; Figure $8 \mathrm{a}-\mathrm{c})$.

Among saline-history dams (Figure 8d), an overall repeated-measures ANOVA revealed a significant main effect of dose $(\mathrm{F}(2,44)=7.40, \quad p<0.01)$ and postpartum experience $(\mathrm{F}(2,44)=4.83, p<0.05)$, but no significant dose $\times$ post-partum experience interaction $(\mathrm{F}(4,44)=1.69, \quad p>0.1)$. Post hoc tests revealed that across increasing doses of morphine $(1.0-10 \mathrm{mg} / \mathrm{kg})$, LS and BS dams with a history of saline treatment spent significantly $(p<0.05)$ more time in the center than $\mathrm{NH}$ dams. Morphine-history dams were similar in the amount of time they spent in the center of locomotor arenas, regardless of postpartum experience (Figure 8e). 

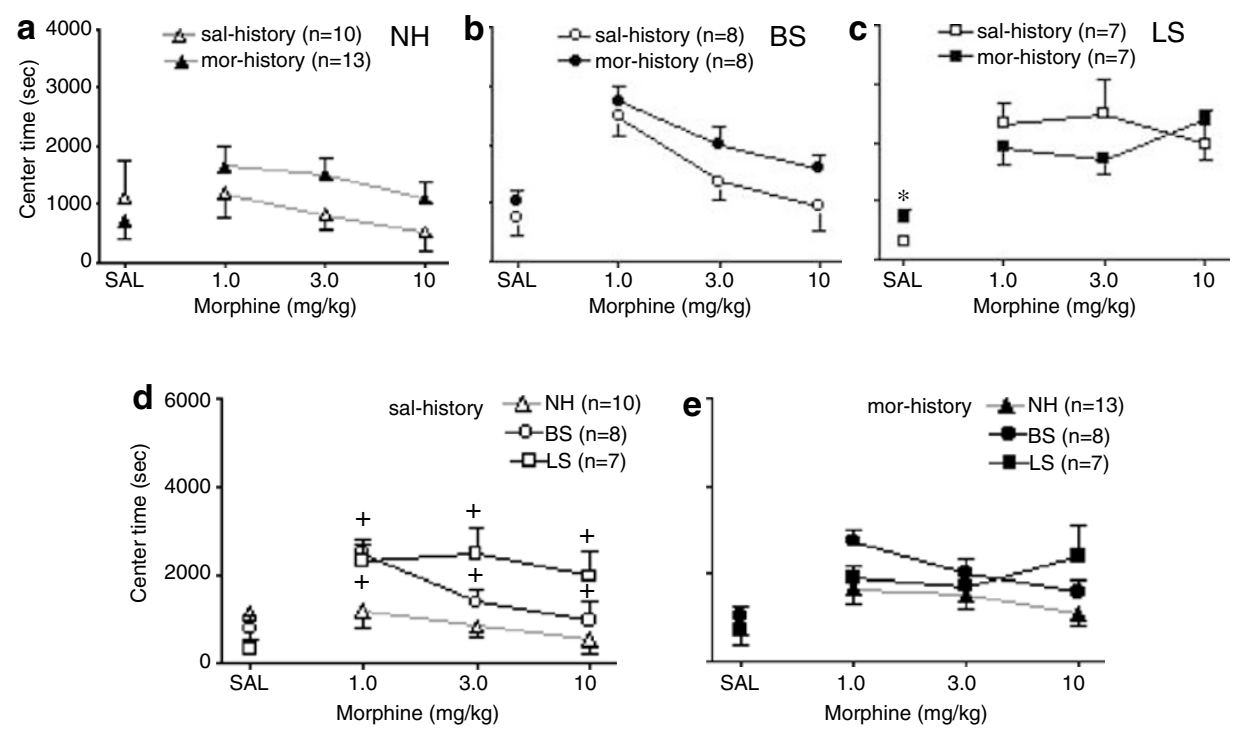

Figure 8 Time (sec) spent in the center of locomotor boxes by LS, BS, and NH dams with a history of either saline (sal; open symbols) or I0 mg/kg of morphine (mor; filled symbols) treatment in response to increasing doses of mor during the expression phase of sensitization. Each point represents the mean ( \pm SEM); $* p<0.05$ compared to the corresponding saline group; $+p<0.05$ compared to $\mathrm{NH}$ dams $(n=7-13 /$ group $)$

\section{DISCUSSION}

Repeated separation of Long-Evans dams from their litters postpartum had a robust and enduring impact on the motor responses of the dams to a novel environment, to conditioning, and to morphine. When tested 4-6 weeks after weaning of their pups, litter-separated dams, especially the 3-h separated animals (LS group), exhibited locomotor activity in a novel environment that differed from that of nonseparated dams ( $\mathrm{NH}$ group). On baseline day 1, the horizontal (LS and BS) and vertical activity (LS) of litter-separated dams declined slower over the course of the session than the activity of NH controls. Furthermore, LS dams exhibited a remarkable lack of habituation in all measures of activity across the 2 baseline days, in contrast to the other two groups. As a consequence, all measures of activity of LS dams were higher than those of the other groups by $150-180 \%$ on the second baseline day. This difference in habituation rates between LS and $\mathrm{NH}$ groups over $2 \mathrm{~h}$ of testing was still present in saline-injected animals (vertical activity), and persisted as a trend for the 10 days of treatment. This is the first evidence that periodic prolonged mother-litter separations of rats can result in long-lasting changes in attentional processes of the mother.

Using similar methods, we previously reported that over 3 consecutive days LS dams spent more time in the center of a novel arena than BS and NH dams, while there were no differences across the groups in horizontal and vertical counts (Kalinichev et al, 2000). A more detailed analysis of those data revealed that, as a trend, LS dams were slower to habituate compared to $\mathrm{NH}$ dams in horizontal and vertical activity. This yielded the differences between LS and $\mathrm{NH}$ groups on those activity measures on the second day of testing that approached, but did not reach, statistical significance. The fact that there was higher variability and fewer animals in our study performed 2 years earlier might have contributed to the small discrepancy in the results of the two studies.

Rats that exhibit high levels of locomotion in a novel environment (high responders, HRs) compared to low responders (LRs) are also more active in an aversive environment typically associated with anxiety, such as open arms of the elevated plus-maze (Kabbaj et al, 2000) or brightly illuminated arenas (Dellu et al, 1993; Kabbaj et al, 2000). Some of the phenotypic differences between 3-h separated and nonseparated dams resemble those between HRs and LRs. For example, similar to HRs, LS dams are more active in a novel environment as well as in open arms of the plus-maze (Kalinichev et al, 2000). In response to startle-inducing, loud auditory stimuli, HRs emit ultrasonic distress vocalizations for a significantly longer period than LR animals (White, unpublished data); under the same conditions LS dams are more likely to vocalize than $\mathrm{NH}$ controls (Kalinichev et al, 2000). Also similar to HR animals (Deroche et al, 1993), LS dams appear to be more sensitive to acute locomotor stimulant effects of morphine (see below). There is accumulating evidence that HR rats are more likely to self-administer amphetamine, cocaine, and nicotine and in higher quantities than LRs (Pierre and Vezina, 1997; Klebaur and Bardo, 1999; Suto et al, 2001). Given the similarity between the LS and HR behavioral phenotypes, it will be interesting to determine if the experience of repeated 3-h separation from the litter also increases the probability of drug self-administration.

Daily administration of $10 \mathrm{mg} / \mathrm{kg}$ of morphine resulted in a pattern of activity that differed between litter-separated and control dams, again most markedly and consistently between LS and $\mathrm{NH}$ dams. For example, daily morphine injections produced rapid and dramatic increases in the horizontal activity of LS and BS dams, which by day 5 exceeded that of corresponding saline-treated controls by almost four-fold, indicative of sensitization. In contrast, the 
horizontal activity of morphine-treated $\mathrm{NH}$ dams required 7 days to increase significantly, at which time it was only 1.6 times higher than that of the corresponding saline-treated animals. Also in the induction phase, the vertical activity of LS dams, suppressed initially by $10 \mathrm{mg} / \mathrm{kg}$ of morphine, rebounded rapidly, reaching levels similar to those of the corresponding saline-treated animals by day 5 , indicative of tolerance. In the expression phase, LS and BS dams with a history of morphine treatment had increases in horizontal activity counts and center time after an injection of saline relative to the activity of the corresponding groups with a history of saline treatment. These increases in activity were robust (130 and $70 \%$, respectively) despite the fact that some of the morphine injections were given in the home cage, a design that usually weakens conditioning. In contrast, the horizontal activity of the $\mathrm{NH}$ group with a history of morphine treatment did not change after the injection of saline.

In the expression phase, sensitization to the stimulant effect of acutely administered morphine was evident in the LS animals that had a history of saline treatment. Across all doses of morphine used $(1.0,3.0$, and $10 \mathrm{mg} / \mathrm{kg})$, the LS dams had higher levels of horizontal activity than either of the other two groups and spent more time in the center of the chamber than $\mathrm{NH}$ dams. Thus, in Long-Evans dams sensitivity to acute locomotor stimulant effects of morphine appears to be increased as a result of periodic prolonged separations from the litter. This sensitization was specific to horizontal movements and center time: there were no group differences in vertical activity after injections of morphine. Differences across the postpartum experience groups in the induction phase of sensitization/tolerance were large, whereas group differences in the expression phase were more modest. Therefore, it is likely that LS, BS, and $\mathrm{NH}$ dams differ in time courses rather than in actual mechanisms of sensitization and tolerance.

The high sensitivity to acute morphine of LS dams with a history of saline treatment might have masked the expression of sensitization to the effects of morphine on horizontal activity by LS dams treated previously with morphine. However, in the case of vertical activity, where there were no group differences among saline-history dams, sensitization to morphine was most apparent in LS dams with a history of morphine treatment.

The experience of repeated separations from the litter during the postpartum period, either prolonged or brief, resulted in phenotypes (LS and BS respectively) that resemble each other in the direction of change. In some behaviors BS dams exhibited changes that were similar in magnitude to those exhibited by LS dams, while in other behaviors BS dams fall between the LS and $\mathrm{NH}$ groups. For example, in the induction phase, BS dams were similar to LS dams in the rate and magnitude of sensitization; however, in baseline activity on B2 and in sensitivity to acute morphine, BS dams resembled $\mathrm{NH}$ controls. We reported previously that BS dams resembled LS dams in the propensity to emit ultrasonic vocalization when startled and in the duration of activity on the open arms of a plus-maze; however, the number of open-arm entries and sensitivity to antinociceptive effects of morphine were similar in BS and $\mathrm{NH}$ dams (Kalinichev et al, 2000). Thus, based on changes in sensitivity to some effects of morphine and some measures of anxiety-like behavior, prolonged and brief separations from the litter during the first 2 weeks postpartum may represent a similar manipulation of different intensity.

There is some evidence that in mixed-sex litters LongEvans dams lick their male pups more often and for a longer period than they lick female pups (Moore and Morelli, 1979; Moore et al, 1997; Agnish and Keller, 1997). There is a possibility that using the same-sex litters can influence some aspects of postpartum separation and its effects on the dam. Regardless of whether similar differences in maternal care also exist in the same-sex litter design, the baseline and morphine-mediated locomotor activity assessed 4-6 weeks after weaning of pups appears not to have been influenced by the litter composition.

In our experiment all the dams were tested 4-6 weeks after pups were weaned. Since female rats resume their cyclicity within only 4-6 days after weaning of their pups, all the experimental subjects had returned to normal cycling well before our study began. Testing for locomotor activity and sensitivity to morphine was performed during random stages of the estrus cycle. The motor activity of female rats varies across the estrous cycle (Quadagno et al, 1972; Steiner et al, 1982); therefore we need to consider the possibility that estrous cycle may have been a confounding variable in this study. However, testing dams at random stages of the estrous cycle did not prevent detecting significant and robust differences in baseline activity and sensitivity to morphine across postpartum experience groups. Furthermore, the testing protocol was the same for rats in the three postpartum experience groups, so any influence of the estrous cycle would have been the same for all groups. Is it possible that the increases in activity are especially dramatic during a particular phase of the estrous cycle? Will the impact of postpartum separation persist if the subjects are ovariectomized? These interesting questions require further investigation.

The plethora of enduring changes that occur as a result of mother-litter separation in the mother appears to parallel those that occur in the other member of the dyad, the offspring (Kalinichev et al, 2001a, 2002a, b). For example, offspring that had experienced daily 3 -h or 15-min separation from their mothers were more active in a novel environment than were corresponding nonseparated controls (Kalinichev et al, 2002a). Daily exposure to $10 \mathrm{mg} / \mathrm{kg}$ of morphine produced rapid and robust sensitization and tolerance in the offspring that experienced 3-h separations. In sharp contrast, corresponding nonseparated controls failed to show these changes. Furthermore, while in 3-h separated offspring exposure to drug-associated cues on a nondrug day resulted in robust (240-260\%) increases in horizontal and vertical activity, in nonseparated animals such increases were confined to vertical activity only. We also reported that periodic $3-\mathrm{h}$ mother-litter separation produces a long-lasting decrease in sensitivity to antinociceptive qualities of morphine both in separated mothers (Kalinichev et al, 2000) and separated male offspring (Kalinichev et al, 2001a). Therefore, periodic mother-litter separations during the first two postpartum weeks appear to result in enduring changes in sensitivity to morphine both in separated mothers and their offspring. These changes 
could reflect significant alterations in endogenous opioid systems.

In the rat, the first few weeks of life are characterized by a significant developmental plasticity of the opioid systems (Bayon et al, 1979; Tsang et al, 1982; Spain et al, 1985; Petrillo et al, 1987). The opioid systems remain remarkably plastic throughout adult life (Kalinichev et al, 2000). Also, both in rats and in humans, the postpartum period is characterized by significant plasticity in multiple neural systems (Russell et al, 2001) and intense reciprocal mother-offspring interactions. Therefore, it is conceivable that periodic mother-litter separations result in enduring changes in opioid systems that occur not only in the offspring but in the mother as well.

There is a large body of evidence indicating that each phase of maternal behavior in the rat is modulated by endogenous opioids. The endogenous opioids appear to be necessary for normal pup-cleaning and placentophagia by the dam at parturition (Mayer et al, 1985), basic attraction to newborns (Zaias et al, 1996), as well as maternal memory (Byrnes and Bridges, 2000). Once maternal behavior is established, endogenous opioids modulate maternal motivation (Panksepp et al, 1994) as well as inhibit active maternal behaviors during nursing bouts in rats and mice (Haney and Miczek, 1989; Mann et al, 1991), thereby contributing to homeostasis in maternal care (Panksepp et al, 1994; Bridges, 1996). Perhaps repeated prolonged separations from the litter or interactions with the separated litter after its return to the nest alter certain characteristics of opioid neurons that regulate maternal behavior. Whether or not repeated separation from the litter results in changes in opioid neurons of the preoptic/hypothalamic area and their regulation of maternal care in the dam remains to be determined. However, the fact that postpartum experience alters locomotor reactivity to a novel environment as well as sensitivity to acute and repeated morphine administration indicates that changes in opioid systems are not restricted to the hypothalamus. At this point we can only speculate unprofitably about the particular changes in opioid systems that occur in dams as a result of postpartum experience. Additional studies are necessary to address this issue directly.

Morphine-induced tolerance and sensitization are thought to be mediated by $\mu$ - and $\delta$-opioid receptors and are long lasting (Babbini et al, 1975; Spanagel et al, 1993; Powell and Holtzman, 2001). The complex neuroadaptive phenomena that are reflected in behavioral sensitization are believed to play an important role in the development of drug seeking, drug taking, and relapse behaviors that characterize addiction (Wise and Bozarth, 1987; Robinson and Berridge, 1993; Berridge and Robinson, 1995). Therefore, studying behavioral sensitization in dams with the experience of disrupted interactions with their offspring might shed new light in understanding environmental factors that lead to increased vulnerability to drug abuse.

\section{ACKNOWLEDGMENTS}

This study was supported by NIH Grant DA11384 and Senior Scientist Award K05 DA00008 to SGH. We thank Paul M Plotsky, PhD, for his valuable advice on the protocol for the early maternal separation procedure.

\section{REFERENCES}

Agnish ND, Keller KA (1997). The rationale for culling of rodent litters. Fundam Appl Toxicol 38: 2-6.

Alberts JR, Gubernick DJ (1983). Reciprocity and resource exchange. A symbiotic model of parent-offspring relations. In: Rosenblum LA, Moltz H (eds). Symbiosis in Parent-Offspring Interactions. Plenum Press: New York, London. pp 7-44.

Babbini M, Davis WM (1972). Time-dose relationship for locomotor activity effects of morphine after acute or repeated treatment. Br J Pharmacol 46: 213-224.

Babbini M, Gaiardi M, Bartoletti A (1975). Persistence of chronic morphine effects upon activity in rats 8 months after ceasing the treatment. Neuropharmacology 14: 611-614.

Bartoletti M, Gaiardi M, Gubellini G, Bacchi A, Babbini M (1983). Long-term sensitization to the excitatory effects of morphine. Neuropharmacology 22: 1193-1196.

Bayon A, Shoemaker WJ, Bloom FE, Mauss A, Guillemin R (1979). Perinatal development of the endorphin- and enkephalincontaining systems in the rat brain. Brain Res 179: 93-101.

Bernet CZ, Stein MB (1999). Relationship of childhood maltreatment to the onset and course of major depression in adulthood. Depression Anxiety 9: 169-174.

Berridge KC, Robinson TE (1995). The mind of an addicted brain: neural sensitization of wanting versus liking. Curr Directions Psychol Sci 4: 71-76.

Boccia ML, Pedersen CA (2001). Brief vs long maternal separations in infancy: contrasting relationships with adult maternal behavior and lactation levels of aggression and anxiety. Psychoneuroendocrinology 26: 657-672.

Brady LS, Holtzman SG (1981). Locomotor activity in morphinedependent and post-dependent rats. Pharmacol Biochem Behav 14: $361-370$.

Bridges RS (1996). Biochemical basis of parental behavior in the rat. In: Rosenblatt JS, Snowdon CT (eds). Parental Care: Evolution, Mechanisms, and Adaptive Significance. Academic Press: New York. pp 205-230.

Byrnes EM, Bridges RS (2000). Endogenous opioid facilitation of maternal memory in rats. Behav Neurosci 114: 797-804.

Caldji C, Diorio J, Meaney MJ (2000a). Variations in maternal care in infancy regulate the development of stress reactivity. Biol Psychiatry 12: 1164-1174.

Caldji C, Francis D, Sharma S, Plotsky PM, Meaney MJ (2000b). The effects of early rearing environment on the development of $\mathrm{GABA}_{\mathrm{A}}$ and central benzodiazepine receptor levels and noveltyinduced fearfulness in the rat. Neuropsychopharmacology 22: 219-229.

Caldji C, Tannenbaum B, Sharma S, Francis D, Plotsky PM, Meaney MJ (1998). Maternal care during infancy regulates the development of neural systems mediating the expression of fearfulness in the rat. Proc Natl Acad Sci USA 95: 5335-5340.

Dellu F, Mayo W, Le Moal M, Simon H (1993). Individual differences in behavioral responses to novelty in rats. Possible relationship with the sensation-seeking trait in man. Pers Individ Diff 14: 411-418.

Deroche V, Piazza PM, Le Moal M, Simon H (1993). Individual differences in the psychomotor effects of morphine are predicted by reactivity to novelty and influenced by corticosterone secretion. Brain Res 623: 341-344.

Fleming AS, Cheung U, Myhal N, Kessler Z (1989). Effects of maternal hormones on 'timidity' and attraction to pup-related odors in female rats. Physiol Behav 46: 449-453.

Fleming AS, Luebke C (1981). Timidity prevents the virgin female rat from being a good mother: emotionality differences between nulliparous and parturient females. Physiol Behav 27: 863-868. 
Fleming AS, O'Day DH, Kraemer GW (1998). Neurobiology of mother-infant interactions: experience and central nervous system plasticity across development and generations. Neurosci Biobehav Rev 23: 673-685.

Fleming AS, Vaccarino F, Luebke C (1980). Amygdaloid inhibition of maternal behavior in the nulliparous female rats. Physiol Behav 25: 731-743.

Haney M, Miczek KA (1989). Morphine effects on maternal aggression, pup care and analgesia in mice. Psychopharmacology 98: $68-74$.

Harro J (1993). Measurement of exploratory behavior in rodents. In: Conn PM (ed). Paradigms for the Measurement of Behavior. Academic Press: San Diego. pp 359-377.

Huot RL, Thrivikraman KV, Meaney MJ, Plotsky PM (2001). Development of adult ethanol preference and anxiety as a consequence of neonatal maternal separation in Long Evans rats and reversal with antidepressant treatment. Psychopharmacology.

Ivinskis A (1970). A study of validity of open-field measures. Aust J Psychol 22: 175-183.

Kabbaj M, Devine DP, Savage VR, Akil H (2000). Neurobiological correlates of individual differences in novelty-seeking behavior in the rat: differential expression of stress-related molecules. $J$ Neurosci 20: 6983-6988.

Kalinichev M, Easterling KW, Holtzman SG (2000). Periodic postpartum separation from the offspring results in long-lasting changes in anxiety-related behaviors and sensitivity to morphine in Long-Evans mother rats. Psychopharmacology 152: 431-439.

Kalinichev M, Easterling KW, Holtzman SG (2001a). Repeated neonatal maternal separation alters morphine-induced antinociception in male rats. Brain Res Bull 54: 649-654.

Kalinichev M, Easterling KW, Holtzman SG (2001b). Early neonatal experience of Long-Evans rats results in long-lasting changes in morphine tolerance and dependence. Psychopharmacology 157: 305-312.

Kalinichev M, Easterling KW, Holtzman SG (2002a). Early neonatal experience of Long-Evans rats results in long-lasting changes in reactivity to a novel environment and morphine-induced locomotor sensitization and tolerance. Neuropsychopharmacology 27: 518-533.

Kalinichev M, Easterling KW, Plotsky PM, Holtzman SG (2002b). Long-lasting changes in stress-induced corticosterone response and anxiety-like behaviors as a consequence of neonatal maternal separation in Long-Evans rats. Pharmacol Biochem Behav 73: 131-140.

Kalivas PW, Stewart J (1991). Dopamine transmission in the initiation and expression of drug- and stress-induced sensitization of motor activity. Brain Res Rev 16: 223-244.

Klebaur JE, Bardo MT (1999). Individual differences in novelty seeking on the playground maze predict amphetamine conditioned place preference. Pharmacol Biochem Behav 63: $131-136$.

Lee MHS, Williams DI (1974). Long-term changes in nest condition and pup grouping following handling of rat litters. Dev Psychobiol 8: 91-95.

Liu D, Caldji C, Sharma S, Plotsky PM, Meaney MJ (2000). Influence of neonatal rearing conditions on stress-induced adrenocorticotropin responses and norepinephrine release in the hypothalamic paraventricular nucleus. J Neuroendocrinol 12: 5-12.

Liu D, Diorio J, Tannenbaum B, Caldji C, Francis D, Freedman A et al (1997). Maternal care, hippocampal glucocorticoid receptors, and hypothalamic-pituitary-adrenal responses to stress. Science 277: 1659-1661.

Mann PE, Kinsley CH, Bridges RS (1991). Opioid receptor subtype involvement in maternal behavior in lactating rats. Neuroendocrinology 53: 487-492.
Mayer AD, Faris PL, Komisaruk BR, Rosenblatt JS (1985). Opiate antagonism reduces placentophagia and pup cleaning by parturient rats. Pharmacol Biochem Behav 22: 1035-1044.

Medrano MA, Zule WA, Hatch J, Desmond DP (1999). Prevalence of childhood trauma in a community sample of substanceabusing women. Am J Drug Alcohol Abuse 25: 449-462.

Moore CL, Morelli GA (1979). Mother rats interact differently with male and female offspring. J Comp Physiol Psychol 93: 677-684.

Moore CL, Wong L, Daum MC, Leclair OU (1997). Mother-infant interactions in two strains of rats: implications for dissociating mechanism and function of a maternal pattern. Dev Psychobiol 30: $301-312$

Nelson EE, Panksepp J (1998). Brain substrates of infant-mother attachment: contributions of opioids, oxytocin, and norepinephrine. Neurosci Biobehav Rev 22: 437-452.

Panksepp J, Nelson EE, Siviy S (1994). Brain opioids and mother-infant social motivation. Acta Paediatrica 397(Suppl): 40-46.

Petrillo P, Tavani A, Verotta D, Robons LE, Kosterlitz HW (1987). Differential postnatal development of $\mu$-, $\delta$ - and $\kappa$-opioid binding sites in rat brain. Dev Brain Res 31: 53-58.

Pierre PJ, Vezina P (1997). Predisposition to self-administer amphetamine: the contribution of response to novelty and prior exposure to the drug. Psychopharmacology 129: 277-284.

Plotsky PM, Meaney MJ (1993). Early postnatal experience alters hypothalamic corticotropin-releasing factor (CRF) mRNA, median eminence CRF content and stress induced release in adult rats. Mol Brain Res 18: 195-200.

Powell KR, Holtzman SG (2001). Parametric evaluation of the development of sensitization to the effects of morphine on locomotor activity. Drug Alcohol Dependence 62: 83-90.

Pryce CR, Bettschen D, Feldon J (2001). Comparison of the effects of early handling and early deprivation on maternal care in the rat. Dev Psychobiol 38: 239-251.

Quadagno DM, Shryne J, Anderson C, Gorski RA (1972). Influence of gonadal hormones on social, sexual, emergence and open field behavior in the rat (Rattus norvegicus). Anim Behav 20: 732-740.

Rauhala P, Idänpään-Heikkilä JJ, Tuominen RK, Männistö PT (1995). Differential disappearance of tolerance to thermal, hormonal and locomotor effects of morphine in the male rat. Eur J Pharmacol 285: 69-77.

Robinson TE, Berridge KC (1993). The neural basis of drug craving: an incentive salience theory of addiction. Brain Res Rev 18: 247-291.

Russell JA, Douglas AJ, Ingram CD (2001). Brain preparations for maternity-adaptive changes in behavioral and neuroendocrine systems during pregnancy and lactation. An overview. Prog Brain Res 133: 1-38.

Servant D, Parquet PJ (1994). Early life events and panic disorder: cause of illness and comorbidity. Prog Neuropsychopharmacol Biol Psychiatry 18: 373-379.

Spain JW, Roth BL, Coscia CJ (1985). Differential ontogeny of multiple opioid receptors ( $\mu, \delta$ and $\kappa)$. J Neurosci 5: 584-588.

Spanagel R, Almeida OFX, Shippenberg TS (1993). Long lasting changes in morphine-induced mesolimbic dopamine release after chronic morphine exposure. Synapse 14: 243-245.

Steiner M, Katz RJ, Carroll BJ (1982). Detailed analysis of estrousrelated changes in wheel running and self-stimulation. Physiol Behav 28: 201-204.

Stewart J, Badiani A (1993). Tolerance and sensitization to the behavioral effects of drugs. Behav Pharmacol 4: 289-312.

Suto N, Austin JD, Vezina P (2001). Locomotor response to novelty predicts a rat's propensity to self-administer nicotine. Psychopharmacology 158: 175-180.

Triffleman EG, Marmar CR, Delucchi KL, Ronfeldt H (1995). Childhood trauma and posttraumatic stress disorder in 
substance abuse inpatients. J Nerv Ment Dis 183: 172-176.

Tsang D, Ng NC, Ho KP, Ho WKK (1982). Ontogenesis of opiate binding sites and radioimmunoassayable endorphin and enkephalin in regions of rat brain. Dev Brain Res 5: 257-261.

Valle FP (1970). Effects of strain, sex, and illumination on openfield behavior of rats. Am J Psychol 83: 103-111.

Walsh RN, Cummins RA (1976). The open-field test: a critical review. Psychol Bull 83: 482-504.

Wigger A, Neumann ID (1999). Periodic maternal deprivation induces gender-dependent alterations in behavioral and neu- roendocrine responses to emotional stress in adult rats. Physiol Behav 66: 293-302.

Wise RA, Bozarth MA (1987). A psychomotor stimulant theory of addiction. Psychol Rev 94: 469-492.

Young EA, Abelson JL, Curtis GC, Nesse RM (1997). Childhood adversity and vulnerability to mood and anxiety disorders. Depression Anxiety 5: 66-72.

Zaias J, Okimoto L, Trivedi A, Mann PE, Bridges RS (1996) Inhibitory effects of naltrexone on the induction of parental behavior in juvenile rats. Pharmacol Biochem Behav 53: 987-993. 